\title{
A Comparison of Talk about Arabs by Iraqi and Polish Women Who Immigrated to Israel in the I950s
}

\begin{abstract}
How does growing up in an Arab country affect Israeli Jewish attitudes toward Arabs? Recent work has gone in two directions, with some arguing that Mizrahim are more hostile toward Arabs and others arguing the opposite. I compare descriptions of Arabs that emerged in life stories of uppermiddle-class-origin Polish and Iraqi women who immigrated to Israel in the 1950s. While there are many similarities in the two groups' stances, about a third of the Poles express a visceral dislike of Arab culture, and a sense that too much Middle Eastern culture will turn Israel into an isolated backwater. This level of distaste is not replicated in degree or substance in any of the Iraqi interviews. Rather, the majority of Iraqis referenced Arabness as part of a desired cosmopolitanism. These Iraqi expressions are sometimes subtle, and appear consequential only in relation to the Poles' statements, demonstrating the importance of a comparison to understand how ethnicity affects attitudes toward Arabs.
\end{abstract}

\section{INTRODUCTION}

$\mathrm{R}$

ECENT HISTORICAL WORK HAS FOUND THAT A VARIETY OF MizRAHI groups expressed some form of identification with Arabs, and that this identification is rooted in their cultural origins in the Arab world. ${ }^{1}$ While this evidence is compelling, it has not been reconciled with quantitative observations that Mizrahim are at least as hawkish and exclusionary as 
Ashkenazim, if not more so. ${ }^{2}$ It is certainly possible to be both hawkish and identified, and indeed the two sets of findings are based on nonoverlapping data. Findings of antipathy are based largely on attitudinal scales regarding the conflict and social integration, while findings of identification are based on the subtleties of speech and other texts. However, the qualitative work also has significant weaknesses. While the surveys are representative and contrast Mizrahi to Ashkenazi responses, the qualitative work is weighted heavily toward studies of political and literary activists and intellectuals ${ }^{3}$, and of Mizrahi voices alone. What is needed is more comparative analyses of nonactivist Mizrahi and Ashkenazi voices in Israel.

I compare life stories of upper middle-class Polish and Iraqi women who immigrated to Israel in the 1950s, and analyze narrative segments that reference Arabs, Palestinians, or Muslims. The comparison is well-situated to evaluate assertions that Middle Eastern origin causes identification with Arabs, because the Iraqis in this study experienced consistent pressure across their life course not to identify. They were educated at the Alliance, a French Jewish school system that taught the Baghdadi middle class and which was oriented toward Westernization and the inculcation of "modern" occupations among Jews. They were taught to value Western over Eastern culture, the girls rarely ventured past the home and Jewish neighborhood, and they made their way into Israel's middle class by self-presenting as Western rather than Arab. ${ }^{4}$ If, despite these pressures, they still appear to 'other' Arabs less than Poles, there is more evidence that a Middle Eastern background enhances identification. Because both groups are non-orthodox, upper middle class, and primarily from Israel's urban center, differences between them are likely to be related to ethnicity rather than the confounding factors that have been identified in the quantitative research.

My findings show that none of my Iraqi respondents directly expresses an Arab or Iraqi identity, and for a variety of reasons I argue that this lack of identification originates from life in Iraq rather than the effect of Israeli life on collective memory. This tends to undermine an argument that this group of Mizrahim is more able to identify with Arabs. Furthermore, while some Iraqis expressed hatred of Arabs, others expressed sympathy with Palestinians, and many of those who expressed hatred later undermined their own statements in the same passage. Thus, the Arab hater image doesn't hold either. Those findings are not new.

Another finding is on the Iraqis' stance toward Arab culture, relative to the Poles' stance. About a third of the Poles' discussions of Arabs express a visceral dislike of Arab culture, and a sense that too much Middle Eastern culture will turn Israel into an isolated backwater. This level of distaste is not 
replicated in degree or substance in any of the Iraqi interviews. Rather, the majority of Iraqis referenced Arabness as part of a desired cosmopolitanism, something that none of the Poles did. These Iraqi expressions are sometimes subtle, and appear consequential only in relation to the Poles' statements, demonstrating the importance of a comparison to understand the effect of ethnicity on attitudes toward Arabs. As this difference is about stances on Middle Eastern culture, rather than politics, it covers an area not normally addressed quantitatively (see Smooha's work). ${ }^{5}$

\section{INTELLECTUAL BACKGROUND}

The idea that Mizrahim could form a cultural bridge to Palestinians has been around for some time. ${ }^{6}$ The empirical evidence used to examine it is historical, ${ }^{7}$ literary, ${ }^{8}$ and biographical, ${ }^{9}$ and it concerns experiences in Arab countries prior to immigration, ${ }^{10}$ in Israel both before statehood ${ }^{11}$ and after, ${ }^{12}$ and travel between Israel and Arab countries. ${ }^{13}$ The mechanisms said to bind Mizrahim to Palestinians and other Arabs include common culture and language, ${ }^{14}$ attachment to Arabic literature that continued after immigration to Israel, ${ }^{15}$ integration or communal cooperation prior to Zionism or the establishment of the state, ${ }^{16}$ communist political movements and strands of Arab nationalist thought that imagined Jews as integral to Arab societies, ${ }^{17}$ and common victimization by Ashkenazi Zionism in Israel. ${ }^{18}$ Relatively few of these studies are focused on life in Israel, but as a body of work they trace forms of cultural and economic integration into Arab societies, and forms of exclusion in Israel, that would tend to result in at least multifaceted attitudes toward Arabs if not full identification. As such, the immigrants emerge as a critical population, and as the complex source of current Mizrahi stances on Arabs. ${ }^{19}$

However, historical work does not uniformly suggest identification; it can also posit and explain disidentification. Here too, the immigrant generation is a critical part of the story. In my own work, ${ }^{20}$ disidentification originated in the Diaspora and was reinforced in Israel. I argued that Jewish modernization projects in Europe and the Middle East encouraged Jews to become Western, which in the Middle East was specifically conceived as becoming less Arab. In Israel, I found that men who could self-present as Western experienced returns to education that were similar to those of Ashkenazim, highlighting the material motivations for continued disidentification in Israel. While I focus on internal pressures toward disidentification, Shenhav ${ }^{21}$ focuses on external pressures. He uses the term 
"de-Arabization" to describe a push on the part of Ashkenazi Zionists to make Mizrahim more recognizably Jewish by becoming less recognizably Arab. The push from Zionists existed both before and after immigration, and while Shenhav's discussion of Mizrahi reactions is complex, a central part of his argument is that once in Israel Iraqis, arguably well-educated Iraqis in particular, engaged in de-Arabization as an "entry ticket" into Israeli society. Those who entered intelligence occupations, for example, sought to demonstrate loyalty and belonging by transforming their intimate knowledge of Arab societies into information Israel could use against Arabs, now conceived as the common enemy of the Jewish state. ${ }^{22}$

Shenhav and I articulate ways that some Mizrahim integrated into Israel's middle class through de-Arabization. However, neither actually shows that these groups took the leap from behaving as non-Arab to an ideological state of antipathy or hawkishness. This is important because the literature articulates two contradictory reactions to the exclusion of Middle Eastern culture in Israel. Shohat argued that Mizrahim were placed on the new border so that they would become victims of Palestinian military action and therefore less likely to unify with Palestinians. ${ }^{23}$ This is another external pressure toward disidentification. Shohat does not see this move as fully successful. Rather, at least some Mizrahim responded to exclusion by identifying with Arabs. Her later work is focused on documenting that identification, even among the Iraqi elite who had the cultural capital necessary to benefit from de-Arabization. ${ }^{24}$ Chetrit's and Roby's complementary studies of Mizrahi activism similarly find that activists saw parallels between the discrimination that they and Palestinians faced, again suggesting that the exclusion of Middle Eastern culture in Israel may have enhanced rather than undermined identification. ${ }^{25}$ Hazkani's data is particularly persuasive. ${ }^{26}$ In his analysis of letters Moroccan soldiers sent home in the 1950s, he found that identification with Moroccans shifted at least three times over the course of ten years, in line with both perceptions of discrimination in Israel and world events. Ashkenazi discomfort with the Middle Eastern appears to have multiple effects on identification and sense of belonging, depending on other factors.

Originally, quantitative work used concepts similar to de-Arabization to explain Mizrahi antipathy toward Arabs. Peres, who first posited the ethnic gap in antipathy, found that $43 \%$ of Mizrahim and Ashkenazim agreed with the statement that "for prejudices to be abolished, Orientals must rid themselves of their shortcomings". He suggested that the resulting effort of Mizrahim to de-Arabize caused them to become less willing than Ashkenazim to integrate socially or residentially with Arabs. However, 
he noted that the ethnic effect on attitudes was weak. ${ }^{27}$ Later quantitative work shifted the discussion entirely, as evidence emerged that non-ethnic, class-related factors statistically neutralized ethnic gaps in antipathy (but see Peled's nuanced argument). ${ }^{28}$ Antipathy, in this body of work, is measured through sophisticated and varied attitudinal scales, assessing, among other things, support for the extreme rightist Kahane and the willingness to cede territory for peace, ${ }^{29}$ willingness to grant political rights or extend the social net to Palestinians, ${ }^{30}$ cooperate with neighboring Palestinians on communal projects, ${ }^{31}$ or engage in social integration by living in the same neighborhood as Palestinians, being friends with Arabs, inviting them into one's home, or allowing one's child to become romantically involved with one. ${ }^{32}$ Ethnic gaps in answers to these items, in turn, are shown to be related to other factors, like education, economic vulnerability, competition with Arab workers, religiousness, and political party. ${ }^{33}$ The conclusion from the quantitative literature is that the ethnic gap is really a class gap.

Does this mean that there is no reason to research the effect of growing up in an Arab country on attitudes toward Arabs? No, for two reasons. First, while the quantitative data usually neutralizes the ethnic effect by accounting for other factors, some of the explanatory factors simply push ethnicity back in the causal chain. For example, Raijman's published data show that with perceived socioeconomic threat controlled, there is no ethnic gap in willingness to grant Arabs rights. ${ }^{34}$ However, her data also show that ethnicity has a direct effect on perceived threat, even after education, income, and occupation are controlled. Second, as Smooha notes, even if it is not clear from the quantitative data that Mizrahim are more hawkish than Ashkenazim, it is certainly clear that they are no less hawkish. ${ }^{35}$ This body of work continues to stand in contrast to expectations from the historical work that Middle Eastern origins generate more positive feelings toward Arabs.

In addition, some work has argued for a flipped gap, in which Ashkenazi liberalism is an ideological cover for extreme antipathy that exceeds that of Mizrahim. ${ }^{36}$ In this argument, Ashkenazim work in two directions at once, building bridges with Palestinians, and strengthening the sense of cultural and historical distance and separation around which those bridges are built. This work is primarily theoretical or indirect. ${ }^{37}$ Shenhav and Hever describe Ashkenazi resistance to the term "Arab Jew", which they attribute to discomfort with any mixing between "Jew" and "Arab". ${ }^{38}$ Yonah examines talk about Russian immigrations, to demonstrate the importance for Ashkenazim of making Israel more European. ${ }^{39}$ Stein looks at how post-Oslo tourism to the Arab world was described in the Israeli media. She 
argues that the media promoted images of Ashkenazi (rather than Mizrahi) tourists, and presented them as encountering an Arab world that was new and unknown. By ignoring those Israeli Jews who would be returning home by visiting the Arab world, the media constructed separation between the Israeli Jewish and the Arab, which could then be bridged by the new peace and consequent travel and interaction. ${ }^{40}$ The argument that Ashkenazi liberalism is a façade is one of the better reasons to use qualitative data, which can read beyond the direct and conscious arguments people make-and for using a comparative approach-which can ask how ethnicity affects both Ashkenazi and Mizrahi stances.

\section{METHODS}

The article draws from a larger project that collected life stories of Polish and Iraqi women who arrived in Israel in the 1950s, when they were young adults (normally I8-22 years old), and in all but one case unmarried. The overall goal is to create a nuanced sense of how ethnicity affects Israeli Jewish lives, one which goes beyond questions of discrimination and examines how ethnicity affects subjectivity. The analytical strategy is to locate relatively small themes that are present in narratives from both groups, and trace similarities and differences among the two groups. In addition to this paper on attitudes about Arabs, for example, I wrote a paper on how the kibbutz figures in the immigration narratives of bourgeois women. The themes I examine range from the highly politicized such as attitudes toward Arabs or gender traditionalism, to the less politicized, such as the experience of caring for parents after the immigration.

The sample consists of fourteen Iraqi and 23 Polish interviews, but of these eleven Poles and one Iraqi did not have enough to say about Arabs to conduct an analysis. While that is a finding in and of itself, its primary effect is that the analysis of content is based on twelve Polish and thirteen Iraqi interviews. As children, the respondents' fathers were primarily in wholesale or other large-scale businesses and their mothers were homemakers, with the exception of one mother who entered the formal labor force after her husband was killed. In Israel, all but one Pole worked in the formal labor force, and all stayed home when their children were young. With the exception of two Poles, one a professor and one a doctor, women from both groups worked in pink collar, female-dominated professions, with many Iraqis bookkeepers, many Poles teachers, and other women working as legal secretaries, lab assistants, nurses, and the like. Analysis of Israel's I96I 
census suggests that this is in line with general patterns for educated Iraqi and Polish female immigrants.

The Iraqi respondents were located through lists of graduates of the Alliance. The Iraqi Jewish community was relatively homogenous, and the "population"-Iraqi Jewish women who graduated from Baghdad's academic Alliance and immigrated to Israel in the 1950s between the ages of I8-22-is small. It is reasonable to infer from the sample's experiences to those of other female Alliance graduates of that cohort. Because of the effect of the Holocaust on this generation of Polish Jews, it was not possible to systematically sample from school lists. Sampling was instead snowball. The snowball samples did have multiple sources, and as such can be considered random. However, given the size and heterogeneity of the Polish Jewish community, one must generalize with caution. ${ }^{41}$

One may ask to what degree the experience of Alliance graduates can be used to assess the experiences of Iraqi or Mizrahi Jews generally. There are parallel questions about the degree to which Polish Jews represent Ashkenazim, given that the Holocaust affected Polish Jews to a greater degree than most other Ashkenazi groups. However, I chose Iraqis for this study not because they are representative of Mizrahim, but because they were similar to Poles. ${ }^{42}$ The goal is to examine ethnic effects among a group whose economic, and in many respects cultural, profiles were similar to each other at the outset, but who in Israel were conceived of as belonging to different ethnic groups. This clarifies the effect of ethnicity, net confounding factors, on thought and action.

In addition, this project conceptualizes ethnic inequality as emerging on multiple sites through multiple dynamics that vary widely by class, gender, age, country of origin, and other factors. In that sense representativeness is neither possible nor desirable; rather each subgroup's experience is part of a greater picture, which can only be developed incrementally. Alliance graduates are important because they experienced pressure to disidentify with Arabs already in the Diaspora, and they also obtained from the Alliance the cultural tools necessary to self-present as Western and nonArab. Throughout the life course they benefitted materially from stressing separation from Arabs, and as such had little reason to ever develop an Arab identity. This is a test at the extremes; if, despite these pressures, Iraqis identify with Arabs, then it is likely that other Jews from Arab countries do so as well. ${ }^{43}$

Interviews were conducted primarily in the respondents' homes, and were unstructured. I conducted all Iraqi and about half of the Polish interviews; the other half of the Polish interviews was conducted by a 
Hebrew University graduate student who is of European origin. My research assistant and I began each interview with a list of topics of interest, which guided our follow-ups in the second phase of the interview and the questions we posed in the third phase. Attitudes toward Arabs were one of the topics on this list. However, this was not one of the topics we raised ourselves; we rather followed up on it when it was raised and did not otherwise pursue it. The results should therefore be conceptualized as an analysis of discussions of Arabs in an interview whose goal was to obtain a general life story. It is in this sense that the lack of talk from half the Poles is itself a finding; it suggests that Poles simply think about Arabs less than Iraqis do.

\section{FINDINGS}

My interviews give me information on three sites on which Iraqi immigrants might construct themselves as closer to or farther from the group we usually call Arabs: interpretation of history, the "bubble" argument that Arabs $^{44}$ and Jews never mixed in Iraq, and descriptions of Arab individuals and Arab culture.

\section{Interpretation of History}

To the degree that Iraqis construct their pre-Israeli existence as one of cooperation rather than tension, identities as Iraqis or Arabs are more likely. Current academic understandings of the history of Jews in Muslim societies more or less agree on a few statements that are in tension with each other: Jews were integral and respected parts of Arab societies, they were minorities who experienced oppression, and this oppression was nothing like the oppression Jews experienced in Christian societies. Beyond that, there is still debate about how exactly exclusion balanced with inclusion, and exactly how colonialism and Zionism affected relations between Jews and Muslim majorities. The political stakes are that to the degree one believes that there was a time when Jews and Muslims got along, one may credit Zionism with relatively more responsibility for the current conflict, and one may believe that increased integration is an attainable political goal. Moreover, Mizrahim who stress historical cooperation may be more open to Arab identities or to political movements that seek to undermine Arab/Jewish and East/West binaries.

None of my respondents expressed a salient Arabic or Iraqi identity. This is not because my sample was especially radical politically. Most 
interviews gave the impression that the experience of Jews in Iraq was mixed, and there was little consensus across the interviews on how these two poles of inclusion and exclusion should be balanced. As a way of summarizing this complexity, I counted how many respondents explicitly made one of five arguments. Three of these five arguments put a positive spin on the history, including I) that historically Jews and Muslims got along, 2) that in the Farhud - which was a three-day mob attack on the Jewish community - many Muslims saved Jews, and 3) that there was some form of reciprocity between Jewish and Muslim communities, such as helping each other out with religious observance. Two of the five arguments are negative, including: I) that Muslims routinely attacked Jews (not including the Farhud), and 2) that the respondent hated Muslims with some connection between the hate and the Iraqi experience. The thirteen Iraqi respondents who made comments about Arabs are split, with four making only positive arguments, three negative arguments, two making both positive and negative arguments, and four interviews with no mention at all. This is one reason that I classify this group as neither Arab haters nor a source of new revolutionary identities; their stances are multiple, varied, and open. While it is unclear from these interviews how they interpreted history in earlier decades, their current narrations would not push the younger generations in any particular direction, but would rather provide rich evidence for any position younger Mizrahim would want to take.

\section{A Jewish Bubble}

A second site on which an argument for identification might be made or undermined is what I call the bubble, i.e., the argument that Jewish society was structurally so separate that the respondents never had an opportunity to develop a sense of belonging to the larger context. Of the thirteen Iraqi respondents who said something about Arabs, six made the bubble argument. Of this six, half - three respondents-described events in other parts of the interview that appeared to undermine the bubble argument. These examples are complex. Three are described below in detail (two from women who made the bubble argument and one who did not). My overall conclusion is that upper middle class Iraqi Jewish women who were unmarried at the time of the immigration grew up seeing but not interacting with Arabs, and that this positioning explains how they do not identify with Arabs but still express relatively positive stances toward Arab culture.

The first undermined bubble argument comes from Victoria and her sister who said that they had no contact with Arabs in Iraq until they finished school and Victoria went to get a visa to study in France. But in 
another part of their interview they describe joining a radio show in which they sang. One of the managers of the show was a young, good looking Arab man who complimented one of the sisters on her voice. When she proudly told her mother about his comment on the quality of her voice, her parents pulled the sisters out of the show, concerned that they would end up marrying an Arab.

So, was there a bubble? On the one hand it is obviously untrue that the impersonal experience at the visa office was the first and only exchange with Arabs. On the other hand, the quick pullout from the radio show to avoid a romance between an Arab and a Jew does support the bubble argument. Victoria and her sister continually emphasize that their parents sought to expand the daughters' horizons, and were willing to take social risks to do so. Yet even for this family, potential intimate contact between unmarried daughters and Arab men was too much and the girls had to be pulled back.

In the second example, Madeline also said that she never saw Arabs in Iraq, but in another section of the interview told me about an Arab family that lived across the street from her house. She learned that that mother's marriage was an arranged marriage by listening to the woman talking to her mother. While describing the neighbor, Madeline mentioned that the neighbor wore an abaya when leaving the house. This description was theoretically important to me because in referencing arranged marriage and covering, Madeline might be Orientalizing, and therefore distancing from, the Muslim neighbor. Because of this possibility, when Madeline later mentioned in passing that her mother wore an abaya to go out, I suggested that that was just like the Muslim neighbor. Madeline rejected this comparison, but gave little detail as to why.

Madeline is resistant to my collapsing of Arab/Jewish cultural boundaries, and this, together with the contradiction in her interview-we saw no Arabs/we had Arab neighbors who came over for tea-supports positions from Shohat, Shenhav, and others that bubble arguments are Israeli strategies for de-Arabization rather than accurate overviews of life in Iraq. However, it is also possible that like Victoria, Madeline's parents set limits to the amount of interaction she could have with the neighbors, and that like Victoria she could see them but not interact with them.

Information from the neuropsychological literature on how perspective shapes what we set to memory helps determine what kinds of statements we can make about how Madeline experienced this neighbor, at the time, as a child in Iraq. This literature would suggest that the full set of details Madeline remembers about a neighbor 60 years after the fact is a valid measure of what occupied her attention at the time, because we 
remember what is important to our developing sense of the world and quickly forget information that seems irrelevant. ${ }^{45} \mathrm{It}$ is not possible to argue here that Madeline gave me the full set of details that exist in her memory. Rather, her current desire to construct her family as different from the neighbor may have caused her to withhold details that would undermine the bubble argument, and this is likely why she shut that part of the conversation down. Still, however, it is possible to assert with some confidence that the details Madeline now reports about the neighbor-details that are oriented toward Orientalizing and distancing from her-has some role in her developing sense of the world back in Iraq, because otherwise, the memory literature tells us, she would not have encoded them at all. It is likely that Madeline shaped the experience into a narrative through hearing her mother process it with others. As such, her encoding of the experience as a story of Jewish/Muslim difference constitutes a "time stamp" of both her own experiences and the frames she obtained from her environment, at the time that the experience occurred. Thus, even if Madeline's bubble argument is an incomplete description of her life in Iraq, it does accurately reflect a process of Jewish/Muslim differentiation that occurred when she was a child in Iraq and that influenced her world view.

In a third example, the respondent did not make a bubble argument but her experiences nevertheless help assess the degree to which a bubble prevailed. Vivienne reports several interactions with Muslims in Iraq. Her aunt wanted her to start kindergarten, something her parents had not set as a priority, and the aunt took it upon herself to find a place for Vivienne even though most schools had already started for the year. Vivienne recounts that she and her aunt went through Vivienne's neighborhood, which was mixed, to try and find a school. They looked at schools that were Muslim, Christian, and Jewish, and settled on the Alliance. Much later, after running from Baghdad to avoid prosecution for joining the Zionist movement, Vivienne lived in her uncle's house in a mixed neighborhood in Basra. On returning to Baghdad she sees an Arab nationalist demonstration, and for the first time realizes that Arabs are also considering nationalist ideas, similar to the Zionism that she herself was exploring. Vivienne narrates the experience as a sudden realization that she is not very different from Arabs after all.

Again, referencing the neuropsychological memory literature, Vivienne's memory of realizing that Arabs can have nationalist feelings too is properly characterized as a memory of expectations defied, and it too, is likely to contain accurate details. ${ }^{46}$ Vivienne's recollections both undermine and support the bubble argument. On one hand, she experienced 
so much integration that she does not even bother to make a bubble argument. Not only did she live in an integrated neighborhood, her aunt considered Muslim, Christian, and Jewish schools (at least in a pinch). On the other hand, the sudden realization that Arabs have subjectivity too underscores a sense of distance from Arabs that predated the realization, and the sudden attention to evidence that Arabs are not what she had thought reveals the degree to which she had previously experienced them as different from herself.

In the discordant pictures Iraqi women now produce of life in Iraq, statements of extreme separation co-exist with evidence of mixing. Respondents do not appear to see the contradiction, and analysis of the memories they describe does tend to suggest that their overall statements reflect an experienced truth. This is because even stories of interaction contain evidence that social structure, parents, and prevailing ideology were acting to keep Jews - or at least unmarried Jewish women—separate from others, and that these limitations strongly structured the subjectivity of this generation of women. With retrospective data such as this I make no claims to completeness, in the sense of having drawn a representative sample of all attitudes an individual had 50 to 60 years ago. However, given evidence from the memory literature that we remember what is important to us at the time, there is fairly strong evidence in these narrations that the concept of the bubble describes a central component of the experience these women had back in Iraq, as children of the Westernizing elite. Thus, the memories elderly Iraqi Jewish women currently narrate reflect social distance that existed at the time that the memories were being encoded, in addition to any political commitments they have to social distance now.

\section{ATTITUDES TOWARD ARAB CULTURE ${ }^{47}$}

Even if social separation prevented these Iraqi women from identifying as Iraqi or Arab, they were still exposed to heterogeneous images of Muslim lives. Even in the examples cited above, one can see the images of Arabs that are being encoded: an attractive radio host, a wealthy neighbor, and nationalists whose ideology is as logical as one's own. Poles, in contrast, experienced Arabs rarely, and when they did it was usually as a conquered population in Israel. This structural difference explains why on the third site of analysis-images of Arabs and Arab culture- the Iraqi women emerge as "othering" Arabs less than the Poles. In essence, the Iraqis have experiences that temper Orientalist thinking, which the Poles do not have. 
My first finding on this site is that Poles often expressed a sense of disgust toward Arab culture. For example, R218 told me that when she arrived in Israel she knew nothing of Arabs, and as a result ended up renting a room in a Palestinian section of Jaffa that was under military rule (Jabaliya). Here is one of her memories from that time:

So the women used to make these kinds of belts, wear them on their bodies, put eggs in them. There they slaughtered the chicken, cleaned it and put it [in the belt] to take it home. Sometimes she [the woman who lived next door] leaves, comes [back] to the house with everything, sometimes comes home, forgive me, the smell was awful ... Because they caught [the chicken] and suddenly all the fat women, so they would do it that way and then put the eggs there and it leaked.

Another Pole, Klaudia feels a sense of isolation and possibly stigma when the Europeans leave and the Middle Easterners are left:

This is a little bit different from the country I thought I was coming to Aziza: to where did you come?

I came home. I thought this is the homeland (הארץ) that is the end of the journey. And now I know from all my friends that their kids are abroad, in the US, Los Angeles, they run away from here. Who is left here? Who is left is who is left. Whoever is worth something, whoever has something in their head, runs. And it hurts. The ones who stay are similar to Arabs or religious or fanatics like the Arabs, and that's who this country will be. On one side the ultra-orthodox and on the other side Arabs. Who will stay here? What else do you want to know? (laughs)

Similarly, R215 complained about how dark people became in Israel (because of the sun) no matter what precautions one took.

Klara, like many Poles, talks about Mizrahim and other Arabs together:

[Early on] I liked Arabic music. Because it was for me something very unusual. I liked the slums of Sheunat Hatikva [Mizrahi area] it was for me very interesting. But after [that period] I can't listen to the music. Not Arabic and not Sephardic. And when she sang yesterday in my exercise class, they put on a CD and she sang, what is her name? ... she shrieks and doesn't sing. I like harmony. And she shrieks and I don't like it. I asked why music is like that? Zehava Ben!

In another powerful segment, Zofia goes into some detail about how her European upbringing did not prepare her for the unpredictable violence 
of Arabs, because in Europe people did not engage in irrational violence. This segment is pertinent because Zofia is a Holocaust survivor, and so presumably was exposed in great detail to irrational violence in Europe. In this sense, her segment appears to dovetail with Klaudia's sense of isolation from global centers; despite Zofia's experience, the Arabness of Israel makes it feel less controlled and more violent than Europe, despite the fact that she left Europe because of the Holocaust. The reason this segment is difficult to classify, however, is that Iraqis often present Arabs as irrationally violent. Thus, while the first four comments had no parallel in the Iraqi interviews, Zofia's overlaps Iraqi statements.

My research locates these Polish attitudes within a Jewish history of Orientalism, in which Jews took up a complicated position as both victims and beneficiaries of European colonialism. The dynamic begins with western Europe's Enlightenment, when French and German Jews were stigmatized as Oriental and a fifth column for the Muslim enemy. Jews' faults were the standard oriental faults; as I note:

Christians demanded that Jews "those unfortunate Asiatic refugees" (Dohm, quoted in Greenberg 1944, I3), reform their lifestyle, values, and social, economic, and educational structure. Friends and foes alike were disgusted by Jewish poverty, by their dark, disorderly ghettos with the "narrow streets, dirt, throngs of people, ... and ceaseless haggling" (Aschheim 1982, paraphrasing and quoting Geothe's description) ... Goethe disliked the rabbis' "fanatic zeal ... wild gesticulations ... [and] piercing outcries" (Barzilay 1955, 221).

Unlike many colonized Middle Eastern populations, who resisted these conceptions and the calls for cultural change, German and French Jews adopted the stigma and launched communal cultural change projects oriented toward making Jews culturally similar to German and French bourgeois Christians. Rathenau's words to his fellow Jews in 1897 illustrate the selfcontempt they often expressed:

Look at yourselves in the mirror!... As soon as you have recognized your unathletic build, your narrow shoulders, your clumsy feet, your sloppy roundish shape, you will resolve to dedicate a few generations to the renewal of your outer appearance. (reprinted in Mendes-Flohr and Reinharz 1980, 232)

This sense of disgust toward the self is replicated in stances toward those considered to be still less Western than the self, including Middle Eastern Jews and ultra-orthodox European Jews, and it is within this frame that one can place the Polish fixation on leaking eggs and shrieking singers, 
or the anxiety of being left alone in a country of violent non-Westerners in which one becomes physically darker.

The Polish attitudes are thus expected. What is not expected, based on Khazzoom's work, is that Iraqis did not follow suit. As Alliance graduatesindividuals who were deeply and daily exposed to Jewish Westernization projects- the Iraqi women should express more or less the same amount of distance from Arabs. However, while the respondents in my study do express Orientalist attitudes, they do not reach the same degree of rejection as the Polish statements do.

In fact, twelve of the thirteen Iraqi interviews characterized the Arabic as part of a desired cosmopolitan existence. Sometimes this was conveyed through narrative structure, by referencing Arabic together with something Western and presenting the whole as cosmopolitan. Examples are:

- Several respondents who constructed the Alliance as a high-quality school by observing that it taught in French, Arabic, and English and that students took Arabic and French matriculations.

- A respondent who said that in school she loved French and Arabic literature and wished she had continued for an advanced degree.

- A respondent who backed up her comment that her family knew the world by noting that they traveled to Syria, Lebanon, and the US.

- Several respondents stressed the high status of their neighborhood by noting that they were ethnically mixed and that an Arab judge or minister also lived there.

- A respondent whose politics leaned to the right said that Israel is for the Jews but that Jerusalem should nevertheless be left international because it is nice to have all three religions present.

Intentionally or not, this narrative structure makes Arabic part of the world rather than separate from it, something that adds to, rather than isolates from, a cosmopolitan existence. ${ }^{48}$

Six interviews had additional segments that presented Arab culture or society as desirable, in ways that contrasted with the Polish denunciations. Two explicitly argued that Iraq was an advanced or a progressive place, one said that her husband went to the University of Istanbul and that it was one of the best universities in the world, and one insisted that Middle Eastern culture is desired in Israel and that restaurants that serve Iraqi food cost much more than others. Suzette recalls:

In the Alliance school, it was usually just Jews, but in kindergarten they send us the daughter of a minister, Arab, Muslim, we thought this was something 
different, all the time we looked at how she dressed, we pulled up her skirt to see if she is dressing like us, and in recess, with her food, if her sandwich is similar to our sandwich. After a week or ten days they took her back because of what we did to her, not an easy life! Because she wasn't appropriate at all! You know, it's like something that doesn't belong (לא שייך)! As kids in kindergarten one thinks that if she is Muslim, her father a minister, probably she is dressed differently, talks differently, eats differently. (laughs)

This is not an easy segment to absorb. The girls are engaging in racial and even sexual harassment of someone who is different from them. It supports the bubble argument, in the sense that social distance is what caused the children to undertake this examination of the new girl in the first place, and the experiment with integration failed rapidly. Still, after this segment the narrator concludes that the little girl was just like them, with the same sandwiches and the same underwear. This is similar to Vivienne's epiphany that Arabs also had nationalist ideals. For all the social distance the segment communicates, it also presents the minister's daughter as culturally on par with the bourgeois Francophile Jewish children. It is quite different from leaking eggs.

Moreover, while five of the thirteen Iraqis used Orientalist concepts to describe Arabs, those statements were more superficial and more qualified than the above Polish segments. They are often self-undermining; following a pattern of first making an Orientalist generalization and then backtracking with evidence of heterogeneity among Arabs. Thus, the personal experience of heterogeneity among Arabs appears to act as a counterforce to Orientalist conceptions obtained through the Alliance and reinforced in Israel. This is a counterforce that Poles do not usually have.

In addition, Iraqi comments on Palestinians often expressed an empathy that tended toward personal if not social identification. Dola, said "they have a place here" ... "it is their land". Gladis said "I have Arabs inside me and have to respect them", just as in Iraq their Arab neighbor had respected them. Stella talks about Palestinians who were let go from her club even though they were excellent workers and overeducated. She says: "also when we were in Iraq the Jews were desperate to work, were desperate to go to the university, no one would let them." Vivienne's description of the Arab nationalist demonstration in Baghdad falls into this category. Positive comments from the Poles tended to be more general, referencing the universal concept of rights, without the same component of identification. This provides a different take on the argument from the literature that Ashkenazi liberalism is a façade; in this sample, it is a more distanced form 
of pro-Palestinian ideology, and does not come with a sense of approval toward Arabic culture.

My overall description of the Polish and Iraqi comments on Arab culture is one of overlapping distributions. On one extreme, when the disgust or sense of isolation become palpable, only Polish respondents can be found, and on another extreme, where empathy becomes palpable, one finds more Iraqis than Poles. Most of the respondents are somewhere in the middle of the range, in a position one might refer to as "Orientalism lite". Iraqi interviews are more likely than Poles to make statements across the continuum, expressing empathy and dislike, stereotyping and undermining of stereotypes in the same interview and often the same passage. Specifically, out of twelve Polish interviews, eight evidenced some form of disgust along the lines described above (the four strongest and one weaker example are described), three Orientalism lite, and two contained positive descriptions of Arabs. In contrast, no Iraqis evidenced disgust, five Orientalism light, and an overlapping eleven cosmopolitanism and positive comments about Arab culture. I argue that despite the bubble, which did exist and which prevented outright identification as Arabs, Iraqis retain variegated images of Arabs from Iraq, and that these experiences continue to temper the influences of an Orientalist education and pressures toward de-Arabization in Israel.

\section{CONCLUSION}

I have compared life stories of upper middle class, primarily urban Iraqi and Polish women who immigrated to Israel in the 1950s, to ask if growing up in an Arab country affects the kind of talk about Arabs that emerges in conversation, when the topics of Arabs, Palestinians, or the conflict are not directly raised by the interviewer. My argument was that if, at this extreme end of the continuum of pressure to de-Arabize, Iraqi Jews still show less antipathy toward Arabs than comparable Polish Jews do, there is one more reason to argue that something about growing up in an Arab country produces positive stances toward Arabs generally. The analysis was inductive, and three themes emerged: interpretation of history, the "bubble" argument, and descriptions of Arab individuals or Arab culture. The first two are specifically Iraqi issues, and the final relied on a comparison of Iraqi and Polish talk.

My findings on the three themes are as follows. First, the Iraqis have varied and even internally contradictory interpretations of the history of Jewish 
experience in Iraq. As such, their narratives do not feed into any particular political position toward the conflict or its resolution. Regarding the bubble, many Iraqi women explicitly presented themselves as having grown up in a community that was removed from its Muslim context, in which they were aware of Muslims but experientially lived in a different world from them. Although details in the interviews sometimes undermine this conclusion, a deeper examination suggests that the bubble is an accurate description of how this group of young, wealthy, unmarried urban women experienced Iraq when they were there. However, the bubble did give women at least visual experience of Muslim Arabs who were wealthy, educated, and Westernized, and whose subjectivity and humanity could sometimes impress itself upon the women. This background, which the Poles do not share, may explain my final finding: despite common exposure to Orientalist ideas that read Arab culture as unfailingly backward, Iraqis remained less committed and less extreme about the application of these ideas than Poles. While some Poles registered disgust about Arab culture, and others perceived it as incompatible with life in a civilized place, Iraqis very consistently imagined Arab culture as part of a desired cosmopolitanism. Importantly, this is not the same as identification with Arabs. The Iraqi women in this study did not want to live in a Middle Eastern society, per se, but rather in a multicultural society in which the Arabic is part of the mosaic.

The political interest in this topic of Arab identification is that Mizrahim have been variously presented as anti-Arab, and therefore not the best ambassadors for peace, and as identified with Arabs, and therefore sources of revolutionary identities for Israel that would locate it more squarely in the Middle East. In response to this debate, my interviews offer no evidence that Iraqi Jewish Alliance graduates had Arab or Iraqi identities, and even offer evidence to the contrary. However, they do suggest that that these immigrants feel more positively toward the incorporation of Arab culture than comparable Poles. As such, Iraqi Jewish immigrants do emerge as a potential source of Israeli identities that undermine global east/west dichotomies. This conclusion cannot be taken too far, however. While the Iraqis would likely enjoy a more multicultural Israel, they did not articulate such a project directly or express political commitment to it. In fact, their stance is articulated weakly enough that I discovered it only through the comparison with Poles. Israeli-born Jews of all types have often used the recollections of these "grandmothers" to assess the Arab/Israeli conflict and its possible solutions, and the next step in analysis would be to ask whether and how this subtle difference among immigrants finds its echoes in the thinking of the Israeli-born. 


\section{Notes}

1. Ella Shohat, "A Reluctant Eulogy: Fragments from the Memories of an Arab-Jew," Women and the Politics of Military Confrontation: Palestinian and Israeli Gendered Narratives of Dislocation (2002): 262-76; Reuven Snir, "Mosaic Arabs' Between Total and Conditioned Arabization: The Participation of Jews in Arabic Press and Journalism in Muslim Societies during the Nineteenth and Twentieth Centuries," Journal of Muslim Minority Affairs 27.2 (2007): 26I-95; Bryan Roby, The Mizrahi Era of Rebellion: Israel's Forgotten Civil Rights Struggle 1948-I966 (Syracuse, 20I5); Sami Shalom Chetrit, Intra-Jewish Conflict in Israel: White Jews, Black Jews (New York, 2009).

2. Sammy Smooha, "Ethnicity as a Factor in the Israeli Jews' Attitudes toward Arabs," in Comparing Cultures and Conflicts (Baden-Baden, 2007), 300-19 [German]; Yochanan Peres, "Ethnic Relations in Israel," American Journal of Sociology 76.6 (197I): I02I-47; Yoav Peled, "Towards a Redefinition of Jewish Nationalism in Israel? The Enigma of Shas," Ethnic and Racial Studies 2I.4 (1998): 703-27; "Ethnic Exclusionism in the Periphery: The Case of Oriental Jews in Israel's Development Towns," Ethnic and Racial Studies 13.3 (1990): 345-67; Majid Al-Haj, "Critical Comment on Yiftachel and Carmon," European Planning Studies 5.2 (1997): 239.

3. See Shay Hazkani, "Arab Mothers Also Cry': Conformity and Dissent in Israeli Soldiers' Letters from the Suez Crisis, I953-I957" (M.A. thesis, Georgetown University, 2010).

4. On getting ahead by exhibiting Westernness, see Orit Bashkin, Impossible Exodus (Palo Alto, 20I7); Aziza Khazzoom, Shifting Ethnic Boundaries and Inequality in Israel: Or, How the Polish Peddler Became a German Intellectual (Palo Alto, 2008).

5. Smooha, "Ethnicity as a Factor." Esther Meir's work also finds that Iraqi bourgeois immigrants feel positively toward Arab culture but don't identify as Arab.

6. Abigail Jacobson and Moshe Naor, Oriental Neighbors; Middle Eastern Jews and Arabs in Mandatory Palestine (Waltham, MA, 20I6); Gil Eyal, The Disenchantment of the Orient: Expertise in Arab affairs and the Israeli State (Palo Alto, 2006); Tom Segev, The First Israelis (New York, 1986).

7. Orit Bashkin, New Babylonians: A History of Jews in Modern Iraq (Palo Alto, 20I2); Jacobson and Naor, Oriental Neighbors; Moshe Behar, "Palestine, Arabized Jews and the Elusive Consequences of Jewish and Arab National Formations," Nationalism and Ethnic Politics 13.4 (2007): 58I-6II; Esther Meir-Glitzenstein, Zionism in an Arab Country: Jews in Iraq in the 1940s (London, 2004); Emily Gottreich, The Mellah of Marrakesh: Jewish and Muslim Space in Morocco's Red City (Bloomington, IN, 2007); Sami Shalom Chetrit, Intra-Jewish Conflict in Israel; Roby, The Mizrahi Era of Rebellion; Hazkani, "Arab Mothers Also Cry"; Lital Levy, "Historicizing the Concept of Arab Jews in the Mashriq," Jewish Quarterly Review 98.4 (2008): 452-69.

8. Reuven Snir, "Till Spring Comes': Arabic and Hebrew Literary Debates among Iraqi-Jews in Israel (1950-2000)," Shofar 24.2 (2006): 92-I23; "Mosaic 
Arabs"; "My Adherence to the Creed of Moses Has Not Diminished My Love for Muhammad's Nation': The Emergence and Demise of Iraqi Jewish Literary Modern Culture," The Jewish Quarterly Review 98.I (2008): 62-87; Ammiel Alcalay, After Jews and Arabs: Remaking Levantine Culture (Minnesota, 1993); Nancy Berg, Exile From Exile: Israeli Writers from Iraq (New York, 2012).

9. Sasson Somekh, Baghdad, Yesterday: The Making of An Arab Jew (Jerusalem, 2007) [Hebrew]; Shohat, "A Reluctant Eulogy"; Naim Kattan, Farewell Babylon (New York, 1980 [1976]); Samir Naqqash, Film: Forget Baghdad: Jews and Arabs-The Iraqi Connection (2007, Zürich); David Kazzaz, Mother of the Pound: Memoirs on the Life and History of Iraqi Jews (New York, 1999); Nissim Rejwan, The Last Jews in Baghdad: Remembering a Lost Homeland (Austin, TX, 2004); Cynthia Kaplan Shamash, The Strangers We Became (Waltham, MA, 2015); Violette Shamash, Memories of Eden: a Journey Through Jewish Baghdad (Evanston, IL, 20Io); Ariel Sabar, My Father's Paradise: A Son's Search for His Jewish Past in Kurdish Iraq (New York, 2009); Lucette Lagnado, The Man in the White Sharkskin Suit (New York, 2007); Marina Benjamin, Last Days in Babylon: The History of a Family, the Story of a Nation (New York, 2006).

10. Bashkin, New Babylonians; Behar, "Palestine, Arabized Jews"; Gottreich, The Mellah of Marrakesh; Alcalay, After Jews and Arabs; Levy, "Historicizing the Concept of Arab Jews".

11. Jacobson and Naor, Oriental Neighbors.

12. Chetrit, Intra-Jewish Conflict in Israel; Roby, The Mizrahi Era of Rebellion; Hazkani, "Arab Mothers Also Cry".

13. André Levy, "To Morocco and Back," in Grasping Land: Space and Place in Contemporary Israeli Discourse and Experience, ed. Eyal Ben-Ari, and Yoram Bilu (Albany, NY, 1997), 25; André Levy, "Homecoming to the Diaspora: Nation and State in visits of Israelis to Morocco," Homecomings: Unsettling Paths of Return (2004): 92-IO8; "A Community that is Both a Center and a Diaspora: Jews in Late Twentieth Century Morocco," Homelands and Diasporas: Holy Lands and Other Places (2005): 68-96.

14. Levy, "Historicizing the Concept of Arab Jews"; Jacobson and Naor, Oriental Neighbors.

15. Snir, "Till Spring Comes"; Berg, Exile from Exile; Bashkin, Impossible Exodus.

16. Gottreich, The Mellah of Marrakesh; Jacobson and Naor, Oriental Neighbors.

17. Bashkin, New Babylonians; Samir, Forget Baghdad.

18. Roby, The Mizrahi Era of Rebellion; Chetrit, Intra-Jewish Conflict in Israel; Hazkani, "Arab Mothers Also Cry".

19. Jacobson and Naor, Oriental Neighbors, and Eyal, Disenchantment of the Orient, show the importance of Ottoman and Mandate era Sephardic, Mizrahi, and Ashkenazi Jews. Not only did these Jews cross and maintain boundaries with Arabs in potentially different ways from Middle Easterners who arrived post-state, the Sephardic groups also saw themselves as cultural and political mediators between the arriving Zionist immigrations and the local populations, as well as between the 
old and new Yishuv. Although these groups lost influence as statehood neared and their small size have not generally been part of the debates about identity, Jacobson and Naor correctly argue that they should be more central to analysis.

20. Aziza Khazzoom, "The Great Chain of Orientalism: Jewish Identity, Stigma Management, and Ethnic Exclusion in Israel," American Sociological Review (2003): 48I-5IO; Shifting Ethnic Boundaries and Inequality in Israel.

21. Yehouda Shenhav, The Arab Jews: A Postcolonial Reading of Nationalism, Religion, and Ethnicity (Palo Alto, 2006).

22. Bashkin's Impossible Exodus notes that despite de-Arabization, Arabic remained in use on multiple sites, and suggests that this could support identification, 195-209. Esther Meir's historical archival work takes a middle line; she demonstrates the attachment of immigrants to the literature, music, food, and other cultural elements they brought from Iraq but underscores that a sense of solidarity with non-Jewish Iraqis was limited to a small cadre of intellectuals. She showcases how immigrants from bourgeois backgrounds used Zionist ideology to articulate their identities, or sought to become part of the Jewish mainstream. See, "A Different Mizrahi Story: How the Iraqis became Israelis," I07-22 in Toward an Anthropology of Nation Building \& Unbuilding in Israel, ed. Fran Markowitz, Stephen Sharot, Moshe Shokeid, and Alex Weingrod (Lincoln, NE, 2015); "Longing for the Aromas of Baghdad; Food, Emigration, and Transformation in the Lives of Iraqi Jews in Israel in the 1950s," in Jews and Their Foodways, ed. Anat Helman, Studies in Contemporary Jewry 28 (2015); Meir-Glitzenstein, "Iraqi Jews in Israel: From 'Refugees' to 'Zionists' and Back Again,” Population Resettlement in International Conflicts (2007): II5-33; Zionism in an Arab Country: Jews in Iraq in the I940s (London, 2004); "Class, Ethnicity and the Rise of Immigrant Leadership; Beer-Sheva in the I950s," Israel Studies 5.2 (2000): 78-106; Between Baghdad and Ramat Gan -Iraqi Jews in Israel (Jerusalem, 2009) [Hebrew].

23. Ella Shohat, "Sephardim in Israel: Zionism from the Standpoint of its Jewish Victims," Social Text 19-20 (1988): I-35.

24. See also Samir, Forget Baghdad; Bashkin, Impossible Exodus.

25. Chetrit, Intra-Jewish Conflict in Israel; Roby, The Mizrahi Era of Rebellion.

26. Hazkani, "Arab Mothers Also Cry."

27. Peres, "Ethnic Relations in Israel"; Smooha, "Ethnicity as a Factor". Weak in two senses: the size of the gap, and relative to the high levels of antipathy both groups expressed. In 1971, Peres noted that answers from both ethnic groups in his survey were so skewed toward the negative that he had to create new answer categories to register levels of hate. This finding is replicated in Smooha's (2007) study.

28. Peled, "Towards a Redefinition of Jewish Nationalism."

29. Peled, "Ethnic Exclusionism in the Periphery."

30. Rebeca Raijman, "Citizenship Status, Ethno-National Origin and Entitlement to Rights: Majority Attitudes towards Minorities and Immigrants in Israel," Journal of Ethnic and Migration Studies 36.I (2010): 87-I06; Ami Pedahzur and Yael 
Yishai, "Hatred by Hated People: Xenophobia in Israel," Studies in Conflict and Terrorism 22.2 (I999): IOI-I7.

31. Yiftachel and Carmon.

32. Peres, "Ethnic Relations in Israel"; Pedahzur and Yishai, ibid.

33. Pedahzur and Yishai, ibid.; Peled, "Ethnic Exclusionism". Residential location on the periphery is mentioned, but, oddly, not usually measured. Peled argues that this is because his entire sample resides in border towns.

34. Raijman, "Citizenship Status."

35. Smooha, "Ethnicity as a Factor."

36. Smadar Lavie, "Mizrahi Feminism and the Question of Palestine," Journal of Middle East Women's Studies 7.2 (20II): 56-88; Rebecca L. Stein, “First Contact' and Other Israeli Fictions: Tourism, Globalization, and 'the Middle East Peace Process'," Public Culture I4.3 (2002): 515-43; Yehouda Shenhav and Hannan Hever, "Arab Jews After Structuralism: Zionist Discourse and the (de) Formation of an Ethnic Identity," Social Identities I8.I (2OI2): IOI-I8; Yossi Yonah, "Israel's Immigration Policies: The Twofold Face of the 'Demographic Threat', Social Identities I0.2 (2004): 195-2I8.

37. Lavie, Mizrahi Feminism and the Question of Palestine."

38. Shenhav and Hever, "Arab Jews After Structuralism."

39. Yonah, "Israel's Immigration Policies."

40. Stein, "First Contact'."

41. In statistical thinking, generalizability is a function of both sample size and standard deviation. When results are extremely consistent within a group, and very different between groups, one can generalize with a smaller sample than when within-group variation is significant. Few narratives followed paths different from the ones I articulate in this article.

42. Aziza Khazzoom, "On Ethnic Categories for Research in Israel: New Data on an Old Issue," Research in Social Stratification and Mobility 23 (2005): I9I-226.

43. Other Mizrahi groups' experiences can be stunningly different. Mizrahim who arrived in Israel without the same prior access to putative Western culture could not benefit from de-Arabization in Israel the way Alliance graduates could. This might cause them to react to exclusion with increased identification with Arabs. Westernized Mizrahim tended to reside in urban areas farther from the conflict.

44. I use the term "Arabs" to refer to Iraqis, Palestinians, and other Arabs, but not to refer to Jews from Arab countries. This is most respondents' usage, and does not reflect an analytical position.

45. The literature on individual memory notes that we forget most of what happens to us within a week, but that information that is important to understanding the world or setting personal goals goes through a process of analysis and gelling into a stable narrative. Once this narrative is established, we permanently lose access to the details that were not incorporated into the narrative, but can retain the narrative and its component details indefinitely (Khazzoom, unpublished). 
46. Memories of expectations defied hold our attention, the memory literature says, because of their unexpected nature. Vivienne is also likely to remember the search for a school accurately, despite her age, because of its importance to her survival and also it was an unusual and highly emotional occurrence. There is reason to analyze these vignettes as though they unfolded the way the respondent says they did.

47. In asking myself after every transcript line what I had just learned about Arabs from the communication, I noted details that a respondent herself framed and highlighted, and details that emerged from conversations that were about something else.

48. This finding is consistent with Meir's contention that elderly Iraqis are returning to some of the cultural practices they abandoned after the immigration, because they remain connected to them.

AZIZA KHAZZOOM is Associate Professor in Near Eastern Languages and Cultures at Indiana University, Bloomington. Her publications include: "De-urbanization and the New Jew: The Kibbutz in Immigration Narratives of Bourgeois Iraqi and Polish Jews Who Immigrated to Israel in the I950s," Israel Studies 19.2 (20I4); Shifting Ethnic Boundaries and Inequality in Israel, or: How the Polish Peddler Became a German Intellectual (Palo Alto, 2008); "The Great Chain of Orientalism: Jewish Identity, Stigma Management, and Ethnic Exclusion in Israel," American Sociological Review 68.4 (2003). 
Copyright of Israel Studies is the property of Indiana University Press and its content may not be copied or emailed to multiple sites or posted to a listserv without the copyright holder's express written permission. However, users may print, download, or email articles for individual use. 